\title{
IgE-mediated cow's milk protein allergy in Singaporean children
}

\author{
Kok Wee Chong, ${ }^{1}$ Si Hui Goh, ${ }^{1}$ Seyed Ehsan Saffari, ${ }^{2}$ Wenyin Loh, ${ }^{1}$ Isabel Sia, ${ }^{3}$ Sherilyn Seah, ${ }^{3}$ Anne Goh
}

\begin{abstract}
Background: Cow's milk protein allergy (CMA) is the second most common food allergy in Singapore. However, there is limited data on local paediatric CMA.

Objective: We aimed to describe the demographics, clinical characteristics, natural history and diagnostic performance of skin prick test (SPT) and cow's milk-specific immunoglobulin E (CM-IgE) in Singaporean children diagnosed with IgE-mediated CMA.
\end{abstract}

Methods: A retrospective review of medical records was conducted for children with an SPT performed to cow's milk between 2011 and 2016 .

Results: There were 355 patients included, 313 cow's milk allergic and 42 cow's milk tolerant. The median age of reaction was 6 months (IQR 4-8). The most common allergic presentation was cutaneous reactions, followed by gastrointestinal reactions. Six patients (1.9\%) reported anaphylaxis at initial presentation and 16 children (5.1\%) experienced anaphylaxis to cow's milk at least once in their lifetime. Most of the CMA patients (81.8\%) acquired natural tolerance by 6 years old. SPT to cow's milk of $\geq 7 \mathrm{~mm}$ and CM-IgE of $\geq 13 \mathrm{kU} / \mathrm{L}$ showed good discriminative abilities in predicting a failed oral food challenge (OFC) outcome.

Conclusion: CMA is a food allergy which commonly presents during infancy, and parents need to be aware of the likelihood of severe allergic reactions, including anaphylaxis. Prognosis for CMA is generally favourable. Future prospective cohort studies are required to better understand the natural history and better define the diagnostic cut-off values for allergy testing in our population.

Key words: anaphylaxis, cow's milk protein allergy, IgE-mediated food allergy, natural history, Singaporean children

From:

${ }^{1}$ Allergy Service, Department of Paediatric Medicine, KK Women's and Children's Hospital, Singapore

${ }^{2}$ Centre for Quantitative Medicine, Duke-NUS Medical School, National University of Singapore, Singapore

3 Yong Loo Lin School of Medicine, National University of Singapore, Singapore

\section{Introduction}

Cow's milk protein allergy (CMA) is one of the most common food allergies in young children worldwide. ${ }^{1}$ CMA can be classified into either immediate-onset immunoglobulin E (IgE)-mediated, where the reaction occurs usually within minutes following ingestion or delayed onset non-IgE-mediated where the effects develop usually after 2 or more hours. ${ }^{2}$ The diagnosis of IgE-mediated CMA is often made by obtaining a history suggestive of an immediate reaction to cow's milk's exposure, coupled with evidence of cow's milk protein sensitization on either a positive skin prick test (SPT) or the presence of cow's

\section{Corresponding author:}

Kok Wee Chong

Allergy Service, Department of Paediatric Medicine, KK Women's \&

Children's Hospital,

100 Bukit Timah Road, Singapore 229899

E-mail: chong.kok.wee@singhealth.com.sg

milk-specific IgE (CM-IgE). Both the SPT and CM-IgE serve to detect the presence of $\operatorname{IgE}$ antibodies but a positive test (SPT wheal size of $\geq 3 \mathrm{~mm}$ larger than the negative control or CM-IgE $\geq 0.35 \mathrm{kU} / \mathrm{L}$ ) cannot differentiate between sensitization alone and clinical allergy. Hence, the gold standard for diagnosis is still the double-blind placebo-controlled oral food challenge (DBPFC). Strict cow's milk protein avoidance with provision of milk alternatives such as hypoallergenic milk formula and management of acute allergic reactions remain the mainstay of management in these children. ${ }^{3}$ Prognosis for 
CMA is favorable as most children outgrow their allergy during childhood. ${ }^{4}$

CMA is the second most common food allergy in Singapore with an estimated prevalence of $0.1-0.44 \% .^{5}$ However, there is limited local data on the demographics and clinical characteristics of CMA. The SPT wheal size and CM-IgE values which can be used as decision points to predict the outcomes of OFCs have not been evaluated in a Singapore or South-East Asian paediatric population. ${ }^{6}$ This retrospective study aimed to evaluate the demographics, clinical characteristics, natural history and diagnostic performance of SPT and CM-IgE in Singaporean children diagnosed with IgE-mediated CMA.

\section{Methods \\ Study design}

In a 5-year period from 2011 to 2016, patients who had a SPT to cow's milk protein were selected for further medical records review. They were identified through our paediatric allergy service's database at KK Women's and Children's Hospital, the main tertiary referral allergy centre in Singapore. These patients had an SPT performed either due to clinical reactions to cow's milk protein, or as part of their work-up for other food allergies or eczema.

Inclusion criteria were 1) patients with proven CMA, as defined by failing an OFC to cow's milk, or a documented immediate reaction to cow's milk in the preceding 6 months coupled with a positive SPT; 2) patients who were cow's milk tolerant (CMT), defined by passing an initial diagnostic OFC to cow's milk, or if they were documented to be taking cow's milk regularly without any reactions at their first presentation to our centre. The diagnosis of anaphylaxis was based on the World Allergy Organization guidelines. ${ }^{7}$ Exclusion criteria were 1) patients who had only sensitization found on SPT, without any prior exposure to cow's milk or dairy products; 2) patients with mixed IgE and non-IgE mediated CMA who had primarily delayed ( $>1$ hour onset) gastrointestinal symptoms. Data on patient demographics, clinical reactions to cow's milk, SPT, CM-IgE results, and milk alternatives were collected. Personal history of rhinitis, atopic dermatitis, asthma and other food allergies were diagnosed by the attending allergist; whilst the rest of personal and family history of atopy were based on parental reports.

\section{Skin prick test and cow's milk-specific IgE measurements}

The skin was prepped with alcohol and cow's milk protein extract (Stallergenes Greer, Lenoir, LC, USA) was applied to the skin using a sterile disposable applicator, Duotip-Test ${ }^{\oplus}$ (Lincoln Diagnostics, Decatur, IL, USA) by trained technicians. Skin tests were performed on the backs of infants and on the forearms of older children. A positive control (histamine) and a negative control (saline) solution were also used. SPT wheal size was measured after 15 minutes. The mean diameter recorded was calculated from the average of the 2 largest measurements that were perpendicular to each other. A positive SPT was taken as a wheal size of $\geq 3 \mathrm{~mm}$ compared to the negative control. CM-IgE were measured by using the ImmunoCAP System FEIA (Phadia AB, Uppsala, Sweden).

\section{Oral Food Challenge}

Patients were selected for OFCs during follow up by the attending allergist to determine tolerance acquisition or as a diagnostic challenge in some equivocal cases. Open OFCs were performed as part of clinical practice while double-blind, placebo-controlled food challenges (DBPCFCs) were performed as part of an ongoing pharmaceutical trial. All hospital-based OFCs were conducted with fresh cow's milk and the procedures and dosage schedules were in accordance with the recommendations set out by the PRACTALL Consensus Report. ${ }^{8}$ Home-based OFCs were conducted by home graded introduction of fresh cow's milk in low risk patients. Patients were considered to have passed an OFC if they successfully tolerated a cumulative dose of $4443 \mathrm{mg}$ of cow's milk protein. ${ }^{8}$

\section{Statistical analysis}

Data were extracted for statistical analysis using SAS software version 9.4 for Windows (SAS, Inc, Cary, NC). Baseline demographic and clinical features were compared between CMA and CMT groups using Mann Whitney and Fisher's exact test for continuous and categorical variables, respectively. The association between demographics, atopic history, SPT wheal size and food-specific IgE concentrations with the risk of cow's milk allergy were tested using univariate and multivariable logistic regression analysis. Receiver Operating Characteristic (ROC) analysis was performed to assess the accuracy of SPT and IgE. Sensitivity, specificity, positive predictive value (PPV), negative predictive value (NPV) and area under the curve (AUC) were calculated for various cut-off points of SPT wheal size and CM-IgE concentrations using univariate logistic regression approach. Statistical significance was set at $\mathrm{P}<0.05$.

\section{Ethical approval}

The study with waiver of informed consent was approved by SingHealth Centralised Institutional Review Board (reference number 2016/2519).

\section{Results \\ Demographics and clinical characteristics}

A total of 355 patients were included in the study, 313 were cow's milk allergic and 42 cow's milk tolerant, at initial presentation to our unit. The median duration of follow up was 1.62 years. The demographics, personal and family history of atopy were summarised in Table $\mathbf{1}$. There was no statistical difference in the racial distribution between the CMA and CMT groups, with the CMA group being $65.81 \%$ Chinese, $11.82 \%$ Malay, $10.86 \%$ Indian and $11.5 \%$ others. The first reaction reported among those with CMA (Table 2) were cutaneous (rash, angioedema) in 92.4\%, gastrointestinal (abdominal pain, vomiting, diarrhea) in $28.8 \%$, respiratory (rhinorrhoea, sneezing, coughing, stridor, wheezing, shortness of breath) in $7.7 \%$ and cardiovascular (hypotension, drowsiness) in $0.6 \%$. Six patients $(1.9 \%)$ reported anaphylaxis at initial presentation and 16 children (5.1\%) experienced anaphylaxis to cow's milk at least once in their lifetime. 
Table 1. Demographic and clinical characteristics of cow's milk protein allergy and cow's milk protein tolerant patients

\begin{tabular}{|c|c|c|c|c|c|}
\hline Variable & $\begin{array}{l}\text { Cow's Milk Protein Allergy } \\
\qquad(\mathbf{n}=313)\end{array}$ & $\begin{array}{l}\text { Cow's Milk Protein Tolerant } \\
\qquad(\mathrm{n}=42)\end{array}$ & p value ${ }^{\star}$ & $\begin{array}{c}\text { Un-adjusted } \\
\mathrm{OR}^{\star *}(95 \% \mathrm{CI})\end{array}$ & $\begin{array}{c}\text { Adjusted } \\
\mathrm{OR}^{\star \star}(95 \% \mathrm{CI})\end{array}$ \\
\hline \multicolumn{6}{|l|}{ Demographics } \\
\hline Male Gender & $182(58.15)^{\varsigma}$ & $28(66.67)$ & 0.320 & $1.42(0.72,2.78)$ & $1.34(0.66,2.72)$ \\
\hline Age at $1^{\text {st }}$ reaction (months) & $6(4-8)$ & - & - & - & - \\
\hline Age at $1^{\text {st }}$ SPT (months) & $10.6(7.3-15.9)$ & $15.1(10.1-39)$ & $<0.001$ & $0.98(0.97,0.99)^{+}$ & $0.98(0.97,0.99)^{+}$ \\
\hline Chinese Ethnicity & $206(65.81)$ & $23(54.76)$ & 0.222 & $1.59(0.84,3.04)$ & $1.85(0.93,3.66)$ \\
\hline \multicolumn{6}{|l|}{ Personal History of Atopy } \\
\hline Rhinitis & $106(33.97)$ & $18(45)$ & 0.218 & $0.63(0.32,1.21)$ & $0.76(0.38,1.54)$ \\
\hline Atopic dermatitis & $226(72.44)$ & $30(75)$ & 0.851 & $0.90(0.43,1.90)$ & $0.84(0.38,1.85)$ \\
\hline Asthma & $34(10.9)$ & $2(5)$ & 0.403 & $1.91(0.50,7.32)$ & $2.21(0.50,9.82)$ \\
\hline Drug allergy & $13(4.17)$ & $1(2.5)$ & 1.000 & $1.19(0.20,7.02)$ & $1.17(0.20,7.04)$ \\
\hline Urticaria/ angioedema $^{\#}$ & $11(3.56)$ & $2(5)$ & 0.651 & $0.59(0.14,2.55)$ & $0.54(0.12,2.36)$ \\
\hline Other food allergies ${ }^{* * *}$ & $180(57.51)$ & $24(60)$ & 0.865 & $0.91(0.47,1.77)$ & $0.87(0.44,1.74)$ \\
\hline \multicolumn{6}{|l|}{ Family History of Atopy } \\
\hline Rhinitis & $148(47.9)$ & $18(45)$ & 0.740 & $1.12(0.58,2.16)$ & $0.97(0.49,1.90)$ \\
\hline Atopic dermatitis & $123(39.81)$ & $16(40)$ & 1.000 & $0.98(0.50,1.91)$ & $0.85(0.43,1.69)$ \\
\hline Asthma & $95(30.74)$ & $5(12.5)$ & 0.016 & $2.87(1.13,7.31)^{+}$ & $2.86(1.11,7.34)^{+}$ \\
\hline Food Allergy & $61(19.81)$ & $4(10)$ & 0.194 & $2.02(0.72,5.62)$ & $1.69(0.60,4.74)$ \\
\hline \multicolumn{6}{|l|}{ Investigation Results } \\
\hline SPT wheal size $(\mathrm{mm})^{\wedge}$ & $6(4-9)$ & $3(3-4)$ & $<0.001$ & $1.52(1.28,1.81)^{+}$ & $1.66(1.35,2.04)^{+}$ \\
\hline IgE to cow’s milk $(\mathrm{kU} / \mathrm{L})^{\wedge}$ & $6.6(1.8-24.1)$ & $1(0.7-1.7)$ & 0.002 & $1.33(0.97,1.81)$ & $1.27(0.96,1.68)$ \\
\hline
\end{tabular}

Abbreviations: SPT = Skin Prick Test; IgE = Immunoglobulin E; OR = Odds Ratio; CI = Confidence Interval

${ }^{\S}$ Frequency (\%) for categorical variables; Median (IQR) for continuous variables

* Mann Whitney U test and Fisher's exact test for continuous and categorical variables, respectively

${ }^{* *}$ Univariate and multivariable logistic regression analysis; adjusted for age at $1^{\text {st }}$ SPT and family history of asthma

${ }_{* * *}$ Clinical diagnosis of other food allergy based on clinical history and positive SPT/ IgE

\# Parental report of patient's history of drug allergy and urticaria/angioedema

' Physician diagnosed rhinitis, atopic dermatitis and asthma

${ }^{\wedge}$ Odds ratio is reported for the risk of $\mathrm{SPT} \geq 3 \mathrm{~mm}$, and serum $\operatorname{IgE} \geq 0.35 \mathrm{kU} / \mathrm{L}$

+ Significant at $\mathrm{p}<0.05$

Table 2. Description of allergic reactions at presentation $(n=313)$

\begin{tabular}{|l|c|c|c|}
\hline Clinical manifestation & Percentage (\%) & Clinical manifestation & Percentage (\%) \\
\hline Cutaneous & 92.4 & Respiratory & 7.7 \\
\hline Any rash & 89.1 & Runny nose & 1.0 \\
\hline Urticarial rash & 42.5 & Sneezing & 1.0 \\
\hline Maculopapular rash & 4.5 & Coughing & 3.2 \\
\hline Eczematous rash & 10.5 & Stridor & 0.3 \\
\hline Perioral rash & 20.8 & Wheezing & 1.6 \\
\hline Rash not described & 16.6 & Shortness of breath & 2.9 \\
\hline Angioedema & 28.8 & & \\
\hline
\end{tabular}

\begin{tabular}{|c|c|}
\hline Clinical manifestation & Percentage (\%) \\
\hline Gastrointestinal & 28.8 \\
\hline Abdominal pain & 0.3 \\
\hline Vomiting & 27.2 \\
\hline Diarrhoea & 2.2 \\
\hline$\underline{\text { Cardiovascular }}$ & 0.6 \\
\hline Drowsiness & 0.6 \\
\hline Hypotension & 0 \\
\hline$\underline{\text { Anaphylaxis }}$ & 1.9 \\
\hline
\end{tabular}




\section{Natural history}

During follow-up of our CMA children, some achieved natural tolerance, as defined by passing a hospital/ home-based OFC. The proportions of CMA children who had outgrown their allergy (defined by either passing a hospital/ home-based $\mathrm{OFC}$ ) by various ages was shown in Figure 1. By 6 years old, $81.8 \%$ of them had self-acquired tolerance.

\section{Milk alternatives}

Milk alternatives consumed by the CMA group included breastmilk (54.3\%), soy milk (44.4\%), extensively-hydrolyzed formula (EHF) (8.6\%), amino acid formula (AAF) (9.6\%), partially-hydrolyzed formula (PHF) (9.6\%) and goat's milk (2.9\%). 27 CMA children (8.6\%) were sensitized to soy milk, of which 18 (5.7\%) had documented allergic reactions to soy.

\section{Diagnostic performance of SPT and CM-IgE}

There was a total of 121 OFCs conducted in 93 patients, of which 58 were hospital-based OFCs. Table 2 showed the diagnostic performance of both the SPT and the CM-IgE tests, using

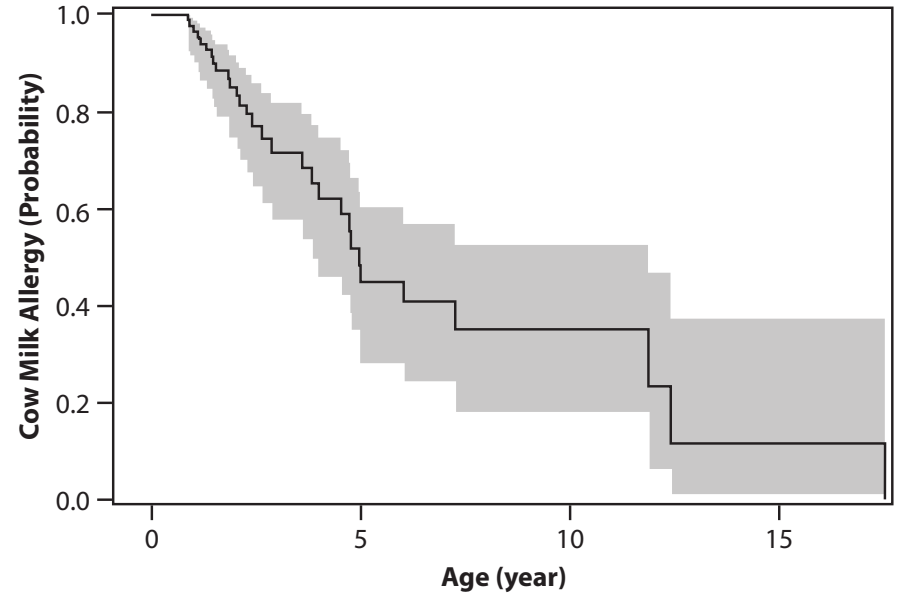

Figure 1. Cow's milk allergy resolution over time

The graph represents the Kaplan-Meier survival curve for development of tolerance (defined by either passing a hospital or home-based cow's milk oral food challenge) to cow's milk over time with the $95 \%$ confidence intervals

Table 3. Diagnostic performance for skin prick test and IgE to cow's milk protein, ROC analysis

\begin{tabular}{|c|c|c|c|c|c|c|c|c|}
\hline Test & $\begin{array}{c}\text { Cut-off } \\
\text { Point }\end{array}$ & $\begin{array}{c}\text { Un-Adjusted } \\
\text { Odds Ratio } \\
(95 \% \text { CI })^{\star}\end{array}$ & p value & Sens & Spec & PPV & NPV & AUC \\
\hline \multirow[t]{8}{*}{ SPT (mm) } & 3 & $3.59(0.94,13.8)$ & 0.0617 & 87.9 & 34.8 & 65.9 & 66.7 & 66.3 \\
\hline & 4 & $3.32(1.08,10.2)$ & 0.0362 & 72.7 & 56.5 & 70.6 & 59.1 & 64.8 \\
\hline & 5 & $6.58(1.96,22.0)$ & 0.0023 & 66.7 & 78.3 & 81.5 & 62.1 & 71.8 \\
\hline & 6 & $13.1(2.89,59.1)$ & 0.0009 & 60.6 & 91.3 & 90.9 & 61.8 & 76.3 \\
\hline & 7 & $14.1(2.26,88.4)$ & 0.0046 & 48.4 & 95.7 & 94.1 & 56.4 & 75.3 \\
\hline & 8 & $9.88(1.56,62.7)$ & 0.0151 & 39.4 & 95.7 & 92.9 & 52.4 & 72.6 \\
\hline & 9 & $6.71(1.02,44.0)$ & 0.0473 & 30.3 & 95.7 & 90.9 & 48.9 & 69.9 \\
\hline & 10 & $18.2(0.86,385)$ & 0.0623 & 27.3 & 100.0 & 100.0 & 48.9 & 74.5 \\
\hline \multirow{11}{*}{$\begin{array}{l}\text { Cow's milk } \\
\text { specific IgE } \\
(\mathrm{kU} / \mathrm{L})\end{array}$} & 0.35 & $13.0(0.39,433)$ & 0.1516 & 100.0 & 23.1 & 65.5 & 100.0 & 82.8 \\
\hline & 1 & $4.08(0.80,20.8)$ & 0.0904 & 84.2 & 46.2 & 69.6 & 66.7 & 68.1 \\
\hline & 2 & $15.8(2.68,93.6)$ & 0.0023 & 79.0 & 84.6 & 88.2 & 73.3 & 80.8 \\
\hline & 3 & $13.9(1.90,101)$ & 0.0095 & 63.2 & 92.3 & 92.3 & 63.2 & 77.7 \\
\hline & 4 & $9.21(1.27,67.0)$ & 0.0283 & 52.6 & 92.3 & 90.9 & 57.1 & 74.0 \\
\hline & 5 & $9.21(1.27,67.0)$ & 0.0283 & 52.6 & 92.3 & 90.9 & 57.1 & 74.0 \\
\hline & 6 & $9.21(1.27,67.0)$ & 0.0283 & 52.6 & 92.3 & 90.9 & 57.1 & 74.0 \\
\hline & 7 & $9.21(1.27,67.0)$ & 0.0283 & 52.6 & 92.3 & 90.9 & 57.1 & 74.0 \\
\hline & 8 & $7.54(1.03,55.2)$ & 0.0468 & 47.4 & 92.3 & 90.0 & 54.6 & 72.3 \\
\hline & 9 & $7.54(1.03,55.2)$ & 0.0468 & 47.4 & 92.3 & 90.0 & 54.6 & 72.3 \\
\hline & 10 & $6.16(0.83,45.7)$ & 0.0754 & 42.1 & 92.3 & 88.9 & 52.2 & 70.5 \\
\hline
\end{tabular}

SPT = Skin Prick Test; IgE = Immunoglobulin E; Sens = Sensitivity; Spec = Specificity; PPV = Positive Predictive value; NPV = Negative Predictive Value; AUC = Area Under the receiver operator characteristic Curve; $\mathrm{CI}=$ Confidence Interval

${ }^{\star}$ Univariate logistic regression analysis 
Table 3. (Continued)

\begin{tabular}{|lcccccccc|}
\hline Test & $\begin{array}{c}\text { Cut-off } \\
\text { Point }\end{array}$ & $\begin{array}{c}\text { Un-Adjusted } \\
\text { Odds Ratio } \\
(\mathbf{9 5 \%} \text { CI })^{*}\end{array}$ & p value & Sens & Spec & PPV & NPV & AUC \\
\hline $\begin{array}{l}\text { Cow's milk } \\
\text { specific IgE } \\
\text { (kU/L) }\end{array}$ & 11 & $6.16(0.83,45.7)$ & 0.0754 & 42.1 & 92.3 & 88.9 & 52.2 & 70.5 \\
& 12 & $6.16(0.83,45.7)$ & 0.0754 & 42.1 & 92.3 & 88.9 & 52.2 & 70.5 \\
& 13 & $20.0(0.87,457)$ & 0.0609 & 42.1 & 100.0 & 100.0 & 54.2 & 77.1 \\
& 14 & $16.2(0.69,382)$ & 0.0840 & 36.8 & 100.0 & 100.0 & 52.0 & 76.0 \\
& 15 & $16.2(0.69,382)$ & 0.0840 & 36.8 & 100.0 & 100.0 & 52.0 & 76.0 \\
\hline
\end{tabular}

SPT = Skin Prick Test IgE = Immunoglobulin E; Sens = Sensitivity; Spec = Specificity; PPV = Positive Predictive value; NPV = Negative Predictive Value; AUC = Area Under the receiver operator characteristic Curve; $\mathrm{CI}=$ Confidence Interval

* Univariate logistic regression analysis

various cut-off values, to predict the outcomes of hospital-based OFCs. SPT to cow's milk of $\geq 7 \mathrm{~mm}$ provided a positive predictive value (PPV) of $94.1 \%$ in predicting a failed OFC outcome. CM-IgE of $\geq 13 \mathrm{kU} / \mathrm{L}$ yielded $100 \% \mathrm{PPV}$ and specificity. A further analysis for those 2 years old or older showed that SPT to cow's milk of $\geq 6 \mathrm{~mm}$ provided a PPV of $95.0 \%$ in predicting a failed OFC outcome, with CM-IgE of $\geq 13 \mathrm{kU} / \mathrm{L}$ similarly yielding 100\% PPV and specificity. Subgroup analysis for those younger than 2 years old could not be performed due to small sample size.

\section{Discussion}

This is the first and the largest retrospective review of IgEmediated CMA children in Singapore. The median age of first reaction was 6 months in our cohort, consistent with the observation that CMA often presents during infancy and early childhood, when milk is still the main component of the child's diet.

In this cohort, the vast majority of patients (92.4\%) reported cutaneous symptoms at initial reaction and few had respiratory and cardiovascular symptoms. In our study cohort, anaphylaxis was reported in 16 cases $(5.1 \%)$, of which 6 cases $(1.9 \%)$ reported anaphylaxis at initial presentation. Allergic reactions to cow's milk in children are mostly mild to moderate but life -threatening anaphylaxis can occur. ${ }^{4}$ In the EuroPrevall birth cohort, ${ }^{9}$ none of the children with suspected CMA reported a history of anaphylaxis. Recent studies reviewing triggers for food-induced anaphylaxis in Singaporean children reported cow's milk to be responsible for only $5.2-7.3 \%$ of all cases. ${ }^{10,11}$ This is in contrast to other recently reported studies, such as a Korean study, which reported cow's milk to be the most common trigger, accounting for $28.4 \%$ of all food-induced anaphylaxis in their cohort, ${ }^{12}$ and a study in New Zealand which reported $21 \%$ of their food-induced anaphylaxis being secondary to cow's milk. ${ }^{13}$ These differences could be explained by variations in patient population, prevalence of type of food allergies (eg. cow's milk was the most common food allergy in the Korean study ${ }^{12}$ while shellfish was most common in the Singaporean study 10), as well as variations in study designs and definitions used in anaphylaxis.

The prognosis for CMA is generally favorable with most patients outgrowing their allergy during childhood. ${ }^{4}$ The duration required to acquire natural tolerance varied significantly between study populations. In a Danish birth cohort study, $56 \%$ of the patients outgrew their allergy at 1 year, $77 \%$ at 2 years, $87 \%$ at 3 years, $92 \%$ at 5 and 10 years and $97 \%$ at 15 years of age. ${ }^{14}$ However, in an Israeli study, less than half of the children diagnosed with IgE-mediated CMA during the first 9 years of life outgrew it. ${ }^{15}$ From a more recent study in Japan, ${ }^{16}$ tolerance acquisition rates in children with IgE-mediated CMA were $32.6 \%, 64.1 \%$, and $84.8 \%$ at 3,5 , and 6 years of age respectively. Similar to the Japanese, $81.8 \%$ of our cohort acquired tolerance by 6 years of age. Variability in natural tolerance could be a result of heterogeneity in study design, outcome measurement, population differences, or a result of a change in the natural history of CMA over these years.

The mainstay of management for CMA in young children is dietary avoidance and replacement with a milk substitute. Breastfeeding is our first line recommendation for infants diagnosed with CMA, hence more than half of our CMA cohort (54.3\%) were being breastfed. Whenever possible, mothers were encouraged to continue breastfeeding and they were not routinely advised for dietary dairy restrictions, unless the infants exhibited symptoms whilst being breastfed. A hypoallergenic formula is one which is tolerated by at least $90 \%$ of infants with proven CMA. ${ }^{17}$ Only EHF and AAF are considered hypoallergenic by this criterion and are the formulas of choice for management of CMA. PHF are not considered hypoallergenic and should not be recommended in infants with proven CMA. In our CMA cohort, 9.6\% were tolerating PHF at the point of diagnosis in the allergy clinic. In a Thai cohort of 382 patients diagnosed with CMA, 35.7\% of them were reported to tolerate PHF well. ${ }^{18}$ Postulations as to why CMA infants tolerated PHF included a possibly milder CMA phenotype and variabilities in the degree of allergenicity (extent of hydrolysis) of the PHFs. As the CMA diagnosis of most of our patients tolerating PHF (86.7\%) were not based on OFC, there is also a possibility that some of these patients were not cow's milk allergic to begin with. Up to $10-14 \%$ of CMA children also present with soy allergy. ${ }^{19}$ For the majority of CMA infants who tolerate soy, soy formulas are nutritionally adequate milk alternatives. They are also more palatable and cost significantly less compared to EHF and AAF in Singapore. In our CMA cohort, close to $95 \%$ of our patients were clinically tolerant of soy and we recommend assessing for soy tolerance in CMA children. 
Due to the high degree of sequence homology between cow's milk and goat's milk proteins, there is significant crossallergy and up to 95\% of CMA patients would also react against goat's milk. ${ }^{4,20,21}$ A notable finding in this study was that there was a small proportion (2.9\%) of CMA infants who were able to tolerate goat's milk. Similar findings had been previously reported in few studies: 1) a small study of 12 CMA patients in Spain, in which $25 \%$ of these patients showed adequate oral tolerance and had negative immunological testing to goat's milk; ${ }^{22} 2$ ) a clinical trial conducted in France also found that 51/55 CMA children tolerated goat's milk for periods ranging from 8 days to 1 year; ${ }^{20} 3$ ) a study in Sweden showed that all 26 confirmed IgE-mediated CMA patients had positive skin test and IgE results to goat's milk, however 2/26 passed a double-blind, placebo-controlled OFC to goat's milk. ${ }^{21}$ It has been surmised that goat's milk could be less allergenic than cow's milk due to its lower alpha-casein content. ${ }^{21}$ However, we do stress that goat's milk tolerance in CMA infants is an exception and goat's milk cannot be recommended as a suitable milk alternative for CMA patients. Similar to the discussion on PHF, these CMA patients who tolerated goat's milk were not challenge-proven to have CMA and hence a possibility of over-diagnosis.

A recent systematic review by Cuomo et al concluded that for children $<2$ years old, SPT wheal size of $\geq 6 \mathrm{~mm}$ or CM$\operatorname{IgE} \geq 5 \mathrm{kU} / \mathrm{L}$ was highly predictive of a diagnosis of CMA. ${ }^{6}$ Results for children older than 2 years old had been a lot more heterogenous, ${ }^{6}$ although a proposed cut-off of SPT wheal size $\geq 8 \mathrm{~mm}$ or CM-IgE $\geq 15 \mathrm{kU} / \mathrm{L}$ by $\mathrm{Du}$ Toit $\mathrm{G}$ et al had been widely accepted. ${ }^{23}$ Our data showed that SPT to cow's milk of $\geq 7 \mathrm{~mm}$ provided a good PPV and specificity of $94.1 \%$ and 95.7\% respectively in predicting a failed OFC outcome. A SPT result of $\geq 10 \mathrm{~mm}$ would provide $100 \% \mathrm{PPV}$ and specificity. CM-IgE of level $\geq 13 \mathrm{kU} / \mathrm{L}$ yielded $100 \% \mathrm{PPV}$ and specificity. Using the conventional cut-off values of SPT $<3 \mathrm{~mm}$ and $\mathrm{CM}-\operatorname{IgE}<0.35 \mathrm{kU} / \mathrm{L}$ yielded high NPV and high sensitivity, at the expense of specificity. In our cohort, using a CM-IgE cutoff of $0.35 \mathrm{kU} / \mathrm{L}$ yielded $100 \% \mathrm{NPV}$ and sensitivity, which is clinically useful to rule out CMA in patients presenting with equivocal or inconsistent history. These cut-off values will be useful in predicting the outcomes of OFCs, potentially reducing the number of OFCs, which can be time and resource consuming, and carry with it a risk of severe allergic reactions. Molecular diagnostic allergy testing involving component resolved diagnostics (CRD) is increasingly used in routine clinical practice. However, we had limited data on CRD in our cohort for analysis.

The strength of this study was that this is the first and largest description of our IgE-mediated CMA children in Singapore, which provided new information on their demographics, clinical presentations and natural history. Based on our data, we also derived cut-off values for SPT wheal size and CM-IgE, which will be useful in predicting the outcomes of OFCs in our own paediatric population. The main limitations of the study stem from its retrospective study design. Most of the CMA patients were diagnosed clinically by the attending allergist based on a clearly documented immediate reaction to cow's milk coupled with a positive SPT, instead of the diagnostic gold standard of an OFC. This is a weakness of the study as some of these patients could have been just sensitized but not truly allergic to cow's milk. Our patients did not undergo regular OFCs to assess for tolerance acquisition but were only selected for OFC when they were deemed by their attending allergist to be at low risk of a reaction. This could cause a bias in our results when we analyzed the predictive cut-off values for SPT and CM-IgE as those patients with higher values who might have been CM tolerant, would have been excluded from our analysis. Our analysis of tolerance acquisition was also based on children who had undergone an OFC and had excluded children who were assumed to be allergic based on their SPT/ CM-IgE results. We had also not taken into account children who were lost to follow up, who could have possibly outgrown their CMA and hence defaulted subsequent clinic visits. Hence the natural history gathered from our study can only be taken as an estimated reference and prospective cohort studies are required to assess these better. Another limitation was that our diagnosis was made based on an open OFC instead of the gold standard of a double-blind, placebo-controlled OFC.

\section{Conclusion}

In conclusion, CMA is a food allergy which commonly presents during infancy, and parents need to be aware of the likelihood of severe allergic reactions, including anaphylaxis. The mainstay of management includes strict avoidance of cow's milk protein. Apart from breastfeeding and hypoallergenic formulas, soy formula can be considered for CMA infants who have been assessed to be soy-tolerant. Goat's milk and PHF should not be recommended as a milk substitute. Most CMA patients acquired natural tolerance by 6 years old. Future prospective cohort studies are required to better understand the natural history and better define the diagnostic cut-off values for allergy testing in our population.

\section{Acknowledgements}

We thank our allergy specialist nurse, Ms Lim Hwee Hoon and skin prick test laboratory technicians for their consistent hard work and excellent patient care.

\section{Conflict of interest}

The authors have no conflict of interest or sources of financial support to report.

\section{Authors contributions}

- Conceptualization: Kok Wee Chong

- Data curation: Kok Wee Chong, Isabel Sia, Sherilyn Seah

- Formal analysis: Seyed Ehsan Saffari

- Manuscript writing: Kok Wee Chong, Si Hui Goh, Isabel Sia, Sherilyn Seah

- Manuscript review: Si Hui Goh, Wenyin Loh, Anne Goh

- Supervision: Anne Goh

\section{References}

1. Prescott SL, Pawankar R, Allen KJ, Campbell DE, Sinn JK, Fiocchi A, et al A global survey of changing patterns of food allergy burden in children. World Allergy Organ J. 2013;6(1):21. 
2. Johansson SGO, Bieber T, Dahl R, Friedmann PS, Lanier BQ, Lockey $\mathrm{RF}$, et al. Revised nomenclature for allergy for global use: Report of the Nomenclature Review Committee of the World Allergy Organization, October 2003. J Allergy Clin Immunol. 2004;113(5):832-6.

3. Fiocchi A, Dahda L, Dupont C, Campoy C, Fierro V, Nieto A. Cow's milk allergy: towards an update of DRACMA guidelines. World Allergy Organ J. 2016;9(1):35.

4. Luyt D, Ball H, Makwana N, Green MR, Bravin K, Nasser SM, et al. BSACI guideline for the diagnosis and management of cow's milk allergy. Clin Exp Allergy. 2014;44(5):642-72.

5. Tham EH, Lee BW, Chan YH, Loo EXL, Toh JY, Goh A, et al. Low Food Allergy Prevalence Despite Delayed Introduction of Allergenic Foods-Data from the GUSTO Cohort. J Allergy Clin Immunol Pract. 2018;6(2):466-475.e1.

6. Cuomo B, Indirli GC, Bianchi A, Arasi S, Caimmi D, Dondi A, et al. Specific IgE and skin prick tests to diagnose allergy to fresh and baked cow's milk according to age: a systematic review. Ital J Pediatr. 2017;43(1):93.

7. Simons FER, Ardusso LR, Bilò MB, Cardona V, Ebisawa M, El-Gamal YM, et al. International consensus on (ICON) anaphylaxis. World Allergy Organ J. 2014;7(1):1-19.

8. Sampson HA, Gerth Van Wijk R, Bindslev-Jensen C, Sicherer S, Teuber SS, Burks AW, et al. Standardizing double-blind, placebo-controlled oral food challenges: American Academy of Allergy, Asthma \& Immunology -European Academy of Allergy and Clinical Immunology PRACTALL consensus report. J Allergy Clin Immunol. 2012;130(6):1260-74.

9. Schoemaker AA, Sprikkelman AB, Grimshaw KE, Roberts G, Grabenhenrich L, Rosenfeld L, et al. Incidence and natural history of challenge-proven cow's milk allergy in European children - EuroPrevall birth cohort. Allergy. 2015;70(8):963-72.

10. Ganapathy S, Lwin Z, Ting DHA, Goh LSH, Chong SL. Anaphylaxis in children: Experience of 485 episodes in 1,272,482 patient attendances at a tertiary paediatric emergency department from 2007 to 2014. Ann Acad Med Singapore. 2016;45(12):542-8.

11. Goh SH, Soh JY, Loh W, Lee KP, Tan SC, Heng WJK, et al. Cause and clinical presentation of anaphylaxis in Singapore: From infancy to old age. Int Arch Allergy Immunol. 2018;175(1-2):91-8.
12. Lee SY, Ahn K, Kim J, Jang GC, Min TK, Yang HJ, et al. A multicenter retrospective case study of anaphylaxis triggers by age in Korean children. Allergy, Asthma Immunol Res. 2016;8(6):535-40.

13. Speakman S, Kool B, Sinclair J, Fitzharris P. Paediatric food-induced anaphylaxis hospital presentations in New Zealand. J Paediatr Child Health. 2018;54(3):254-9.

14. Høst A, Halken S, Jacobsen HP, Christensen AE, Herskind AM, Plesner K. Clinical course of cow's milk protein allergy/intolerance and atopic diseases in childhood. Pediatr Allergy Immunol. 2002;13(s15):23-8.

15. Levy Y, Segal N, Garty B, Danon YL. Lessons from the clinical course of IgE-mediated cow milk allergy in Israel. Pediatr Allergy Immunol. 2007;18(7):589-93.

16. Koike Y, Sato S, Yanagida N, Asaumi T, Ogura K, Ohtani K, et al. Predictors of Persistent Milk Allergy in Children: A Retrospective Cohort Study. Int Arch Allergy Immunol. 2018;175(3):177-80.

17. Høst A, Koletzko B, Dreborg S, Muraro A, Wahn U, Aggett P, et al. Dietary products used in infants for treatment and prevention of food allergy. Joint Statement of the European Society for Paediatric Allergology and Clinical Immunology (ESPACI) Committee on Hypoallergenic Formulas and the European Society for Paediatric Gastroenterology, Hepatology and Nutrition (ESPGHAN) Committee on Nutrition. Arch Dis Child. 1999;81(1):80-4.

18. Ngamphaiboon J, Chatchatee $P$, Thongkaew T. Cow's milk allergy in Thai children. Asian Pacific J Allergy Immunol. 2008;26(4):199-204.

19. Kattan JD, Cocco RR, Järvinen KM. Milk and soy allergy. Pediatr Clin North Am. 2011;58(2):407-26.

20. Fiocchi A, Brozek J, Schünemann H, Bahna SL, von Berg A, Beyer K, et al. World Allergy Organization (WAO) Diagnosis and Rationale for Action against Cow's Milk Allergy (DRACMA) Guidelines. Pediatr Allergy Immunol. 2010;21:1-125.

21. Bellioni-businco B, Paganelli R, Lucenti P, Giampietro PG, Perborn H Businco L. Allergenicity of goat's milk in children with cow's milk allergy. J Allergy Clin Immunol. 1999;103(6):1191-4.

22. Infante Pina D, Tormo Carnice R, Conde Zandueta M. Use of goat's milk in patients with cow's milk allergy. An Pediatr (Barc). 2003;59(2):138-42.

23. Du Toit G, Santos A, Roberts G, Fox AT, Smith P, Lack G. The diagnosis of IgE-mediated food allergy in childhood. Pediatr Allergy Immunol. 2009;20(4):309-19. 